\title{
Para além dos aspectos nutricionais: uma visão ambiental do sistema alimentar
}

\author{
Déborah Takeuti ${ }^{1}$ e Julicristie M. Oliveira ${ }^{2}$
}

Há ainda escassez de estudos que abordam o tema da alimentação de forma mais abrangente, para além dos aspectos nutricionais. O objetivo do presente estudo é trazer uma reflexão acerca dos impactos ambientais do sistema alimentar hegemônico. Considerando métodos utilizados na cadeia produtiva, desde o plantio até as escolhas alimentares, este sistema alimentar compreende uso exacerbado de combustíveis fósseis, agrotóxicos, água, terra para a produção de commodities, com comprometimento da biodiversidade, qualidade da água, solo e alta emissão de gases do efeito estufa. Sua organização se volta para atender as pressões de consumo e os padrões dietéticos insustentáveis, enquanto há persistência de insegurança alimentar e nutricional em várias camadas da população. Neste sentido, destaca-se a produção e consumo de carnes, especialmente a bovina, pelos seus altos custos ambientais. Aponta a necessidade de mudanças nos padrões de consumo, com ênfase nas práticas dietéticas mais adequadas ao ambiente, sem esquecer os simbolismos que permeiam o comer. Assim, a discussão dos impactos ambientais deste sistema alimentar pode fazer parte das agendas das associações e instituições da área de Nutrição, Saúde Coletiva e Ambiente, entre outros. Estudos e esforços subsequentes podem evidenciar esta inter-relação, tornando seu entendimento mais palpável, rumo a outros sistemas de produção de alimentos e outros padrões dietéticos.

Palavras-chave: gases do efeito estufa, hábitos alimentares, impacto ambiental, meio ambiente, produção de alimentos.

\section{Beyond nutritional aspects: an environmental view of food system}

Feeding studies that go beyond the nutritional aspects are scarce. The aim of this paper is to reflect on environmental impacts of the hegemonic food system. Considering the methods used in the production chain, from cultivation to food choices, this food system comprehend the exaggerated use of fossil fuels, pesticides, water, land for the production of commodities, which compromise biodiversity, water and soil quality, and high greenhouse gas emission. Its organization is made to meet consumption pressures and the unsustainable dietary patterns, once the maintenance of food and nutrition insecurity in different strata is persistent. In this sense, the production and consumption of meat, especially beef, must be highlighted for its high environmental costs. Also, it points out to the need of changing consumption patterns towards dietary practices. These practices must be more suitable for the environment, whereby the meaning of eating cannot be forgotten. Thus, the discussion about the environmental impacts of this food system must be part of the agenda of associations and institutions in the Nutrition, Public Health and Environment areas, among others. Further studies and efforts may emphasize this interrelation, promoting understanding towards other food systems and other dietary patterns as well.

Key-words: greenhouse gases, eating habits, environmental impact, environment, food production.

\footnotetext{
${ }^{1}$ Graduada em Nutrição. Faculdade de Ciências Aplicadas, UNICAMP.

2 Professora Doutora. Faculdade de Ciências Aplicadas - FCA/UNICAMP. Correspondência: Rua Pedro Zaccaria no 1.300, Jardim Santa Luiza, Limeira, SP. CEP. 13484-350. Tel (19) 37016720.E-mail: julicristie.oliveira@fca.unicamp.br.
} 


\section{INTRODUÇÃO}

Estudos com abordagem mais abrangente do tema da alimentação, para além dos aspectos nutricionais, ainda são escassos. Apesar deste fato, pesquisas de diversas áreas do conhecimento e, especialmente as interdisciplinares, têm se tornado mais frequentes, evidenciando as inter-relações entre a alimentação e questões globais, tais como os impactos ambientais de diferentes sistemas de produção de alimentos e de padrões dietéticos.

Vive-se um momento paradoxal, pois apesar do aumento na produção de alimentos [1], há persistência de Insegurança Alimentar e Nutricional (IAN), problemas carenciais e de má nutrição que são, em certa medida, consequência da utilização das terras agriculturáveis a serviço do agronegócio, da produção de commodities e de biocombustíveis, das perdas e desperdícios, e da ausência de sustentabilidade dos padrões dietéticos praticados por camadas favorecidas da população. Ademais, observa-se que, da mesma maneira que os avanços tecnológicos permitiram rápida expansão da agricultura moderna, ampliação da produção e consequente consumo dos alimentos, os impactos ambientais do processo apresentam-se igualmente progressivos [2,3].

A consciência pública sobre as questões ambientais globais têm trazido um chamado a práticas sustentáveis na produção de alimentos [4] e administração responsável dos recursos finitos [5]. Segundo Leiztmann ${ }^{[6]}$, práticas de sustentabilidade em Nutrição relacionam-se com a distribuição justa dos alimentos por meio do comportamento alimentar ecológico e preventivo, pressupondo-se que a reavaliação de valores comuns são necessários para o alcance de um novo entendimento de qualidade de vida. A adequação quantitativa de alimentos precisa ser pensada por todos, visando a garantia da Segurança Alimentar e Nutricional (SAN). Entretanto, aspectos como a biodiversidade, base da variedade alimentar, devem ser considerados também por ter papel fundamental no enfrentamento dos desastres ambientais e suas consequências. Devido à importância destes aspectos globais e locais, ressalta-se a necessidade de atuação de vários outros profissionais neste campo da Nutrição, salientando seu caráter interdisciplinar, em especial quando se trata da produção de conhecimentos e saberes [7].
Assim, o presente estudo tem por objetivo trazer uma reflexão acerca dos impactos ambientais do sistema alimentar hegemônico, com o interesse em discutir realidades e perspectivas sobre questões de um mundo onde a sustentabilidade e a preservação de recursos constituem-se em grandes desafios.

\section{CONTEXTUALIZANDO: AMBIENTE, PRODUÇÃO DE ALIMENTOS E NUTRIÇÃO}

O desenvolvimento tecnológico influencia, de modo importante, diversos aspectos da vida contemporânea. Com isso, questões básicas como os padrões de consumo alimentar e suas consequências tornam-se objetos de reflexão. Os impactos ambientais da produção de alimentos são determinados inicialmente pela produção agrícola. Os métodos convencionais incluem tecnologias desenvolvidas com vistas a aumentar a produção para atender a demanda de padrões exacerbados de consumo. Assim, em nome da alta produtividade, há o uso intensivo de recursos tecnológicos, como pesticidas, herbicidas, fungicidas, inseticidas e fertilizantes sintéticos que se associam a maiores níveis de contaminação de alimentos. Além disso, estas mesmas práticas de agricultura apresentam notáveis consequências sociais, econômicas e ambientais [ ${ }^{6}$. Alguns impactos são a poluição do ar, da água, do solo, erosão, perda de biodiversidade, aumento do consumo de energia e desperdício de alimentos [4,5,8,1,10]. Em contrapartida, as produções orgânicas e agroecológicas, ao considerarem o controle natural de pestes, rotação de culturas, promovem o desenvolvimento da produção com uso de adubo orgânico, resultando em mitigação dos impactos ambientais [11]. Desta forma, estes sistemas produtivos precisam ser apoiados globalmente ${ }^{[6]}$, com incentivo ao processamento mínimo e otimização e reorganização do abastecimento e transporte. Consequentemente, ao mitigar os impactos ambientais, promove-se também a saúde humana, pois como resultado da supressão do uso de substâncias cujos efeitos são maléficos ou incertos, há redução das doenças crônicas nãotransmissíveis (DCNTs) pelo consumo de alimentos mais saudáveis e com menor risco de contaminação, além da garantia da SAN [12].

Ademais, a agricultura urbana e periurbana podem ser consideradas estratégias de redução dos impactos ambientais, quer seja pelo potencial reflexivo que provocam a partir do encurtamento da distância entre a produção do alimento e o consumo, quer seja pelo não uso de insumos químicos, redução ou isenção 
de uso de combustíveis fósseis em seu processo produtivo, incluindo o transporte a longas distâncias. Deve-se pontuar também o potencial de empoderamento dos atores sociais urbanos e periurbanos envolvidos com o cultivo que vivenciam a experiência de (re)conexão com a natureza e de responsabilidade ambiental. É evidente que atividades de produção de alimentos em regiões urbanas e periurbanas necessitam de um planejamento adequado, especialmente em relação à sua localização geográfica, bem como à investigação da contaminação do solo e da qualidade do ar que podem impactar negativamente na qualidade do alimento produzido.

\section{IMPACTOS AMBIENTAIS DESTE SISTEMA ALIMENTAR}

A Figura 1 contempla os impactos ambientais que serão considerados no texto, quais sejam, a complexidade do sistema, suas consequências e influência dos hábitos alimentares. Sabe-se que toda a cadeia produtiva de alimentos gera uma série de consequências [13,14]. Assim, maiores impactos ambientais resultantes do aumento da produção podem ser observados, principalmente, pela inclusão de maquinários ao longo do processo e de métodos intensivos. Dentre estes, o uso de terras que leva à diminuição da biodiversidade, consumo de combustíveis fósseis, poluição, aumento da emissão dos gases de efeito estufa (GEEs) e consumo de água. Observando as vias do processo, tem-se também que a criação de animais leva a maior utilização de recursos, principalmente por conta da produção de ração. A figura, assim, ilustra uma rede interligada de acontecimentos complexos.

Figura 1. Esquema representativo da inter-relação entre escolhas alimentares, sistema alimentar e impactos ambientais

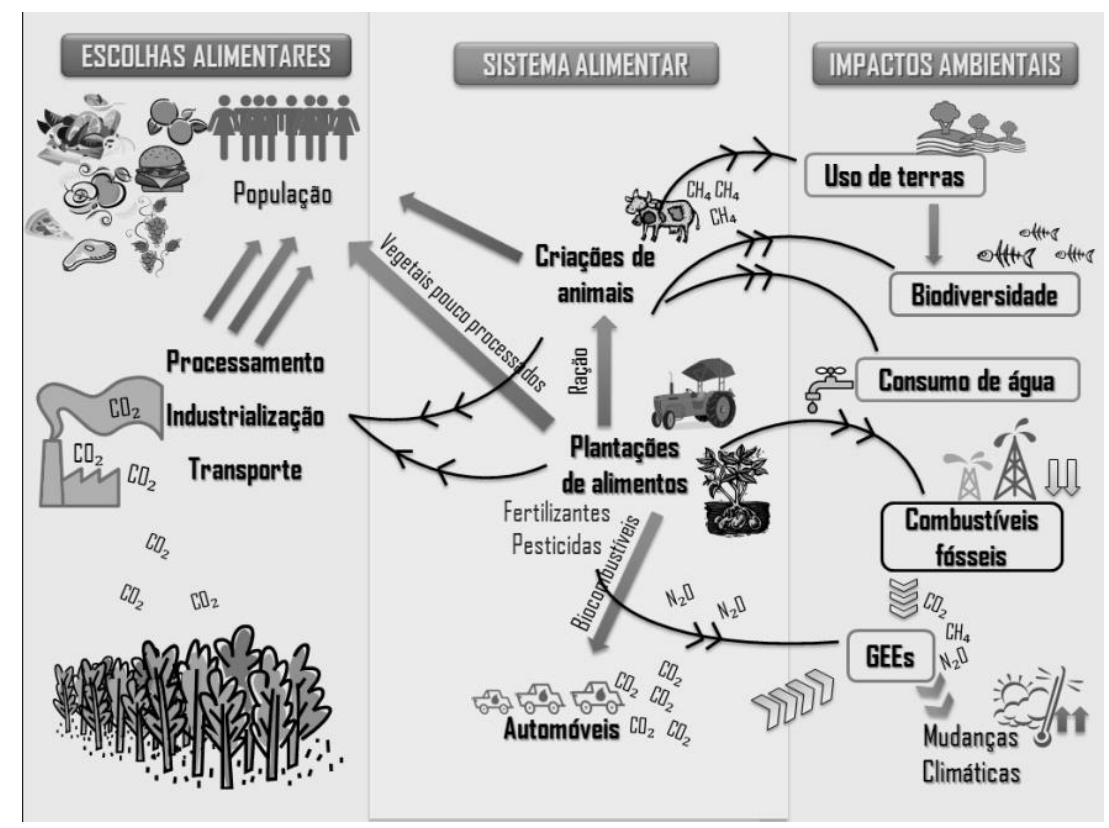

Fonte: Organizado pelas autoras.

Alguns estudos buscaram identificar quais alimentos impactam o meio ambiente de forma mais acentuada. Produtos de origem animal e alguns de origem vegetal cultivados em monocultura ${ }^{[10]}$ foram elencados como os mais nocivos. Há, assim, a necessidade de promoção de dietas mais favoráveis e, aparentemente, ao se tratar de saúde e ambiente, não há grandes controvérsias: padrões dietéticos mais 
saudáveis também se associam a redução de impactos ambientais [12,15,16]. Segundo Baroni et al. [10], ao compararem os padrões dietéticos onívoro, vegetariano e vegano com base na produção intensiva ou orgânica dos alimentos, em relação às consequências nos ecossistemas e na saúde humana, apontam que dietas que incluem alimentos orgânicos e que suprimem a carne e outros produtos de origem animal são as mais adequadas.

A maioria dos estudos sugere que a prática de uma alimentação saudável perpassa pelo aumento do consumo de alimentos de origem vegetal (cereais, leguminosas, oleaginosas, hortaliças e frutas,) e redução do consumo de alimentos de origem animal (carnes e derivados, leite e derivados, ovos), sendo um princípio aplicável principalmente a indivíduos sedentários [ $[$. Os resultados dos estudos que buscam identificar os chamados pontos críticos do impacto ambiental destacam as mudanças nos padrões de dieta que resultariam em maiores benefícios ao meio ambiente. Desta forma, analisando-se cada alimento separadamente, constata-se que as carnes de ovelha e a bovina são os itens de maior impacto, seguidas de leite e derivados, carne de porco, ovos e aves [10]. Assim, padrões dietéticos vegetarianos/veganos ou com reduzida ingestão de carne bovina (semi-vegetarianos) seriam os mais sustentáveis.

Um conceito que também pode ser discutido é o de dieta sustentável publicado pela Food and Agriculture Organization [17] (FAO) em 2010:

Dietas sustentáveis são dietas que geram menores impactos ao meio ambiente, contribuindo para a segurança alimentar e nutricional assim como uma vida saudável a gerações atuais e futuras. Estas dietas contribuem para a proteção e respeito pela biodiversidade e ecossistemas, são culturalmente aceitáveis, economicamente justas e acessíveis, adequadas, seguras e saudáveis do ponto de vista nutricional e ao mesmo tempo otimizam recursos naturais e humanos (Food and Agriculture Organization, 2010, p.7) [17].

Tal definição reconhece a interdependência entre produção e consumo, necessidades alimentares e recomendações nutricionais, ao mesmo tempo em que confirma que a saúde do ser humano não pode ser desconectada da saúde dos ecossistemas. Entretanto, é fundamental pensar uma educação alimentar e nutricional que problematize as escolhas alimentares para que se tornem consonantes às possibilidades ambientais, à biodiversidade, à cultura de cada país e região.

\section{USO DE TERRAS, CRIAÇÃO DE ANIMAIS E EMISSÃO DE GASES DE EFEITO ESTUFA}

Estudos apontam que mais de um terço de toda área livre de gelo é usada para produção de alimentos [9]. Para a criação de animais, o uso de terras está ligado ao desflorestamento para pastagens ${ }^{[10,18]} \mathrm{e}$ utiliza $70 \%$ de toda terra direcionada para a agricultura e $30 \%$ da superfície de terra ${ }^{[9]}$.

A cada ano, 17 milhões de hectares de floresta tropical são destruídos, e a tendência é o aumento desta prática. Segundo o Instituto de Pesquisas Espaciais do governo brasileiro, houve um aumento de $40 \%$ no desflorestamento entre 2002 e 2003. Mesmo que nem toda a terra seja utilizada para a criação de gado, 88\% da terra desmatada da Floresta Amazônica tem sido usada para pastagem [19]. Desta forma, o aumento do consumo de proteína animal em várias partes do mundo tem se constituído em uma mola propulsora para o aumento da ocorrência destes impactos ambientais [1].

Entretanto, se considerássemos a redução no consumo de carnes pela população mundial haveria, consequentemente, redução no volume da criação e da necessidade de ração. Assim, grande parte da produção de grãos se redirecionaria para a alimentação humana, contribuindo com maior eficácia nos esforços para a erradicação da IAN [16]. Além disso, existem questões de Saúde Coletiva, como o estabelecimento de doenças zoonóticas - gripe suína, a doença priônica "Encefalopatia Espongiforme Bovina" e a influenza aviária [1,5], o elevado consumo de ácidos graxos saturados, colesterol, substâncias potencialmente carcinogênicas formadas durante a cocção, sódio e nitritos de adição associados à maior ocorrência de DCNTs como câncer, doenças cardiovasculares, sobrepeso e obesidade [20,21].

Por conta do elevado consumo, recomendações são publicadas por órgãos de pesquisa como o World Cancer Research Fund [20], que orienta a ingestão de no máximo $500 \mathrm{~g} / \mathrm{semana}$ de carne, ou $71,4 \mathrm{~g} /$ dia, incluindo carne vermelha (bovina e suína) e processados para a prevenção de câncer. No Brasil, o Ministério da Saúde [22], recomenda a ingestão de uma 
porção de $100 \mathrm{~g} /$ dia para uma dieta saudável. Ainda assim, o consumo de carne no Brasil é bastante elevado. Em estudo realizado por Carvalho et. al. [21], em São Paulo, a média de ingestão de carne vermelha e processada, em 2003, excedeu o padrão recomendado pela WCRF [20] de 74,42g/dia em 63,6g e $6,6 \mathrm{~g}$ a mais, para homens e mulheres, respectivamente. Considerando todo o Brasil, as Pesquisas de Orçamentos Familiares (POF), de 2008 e 2009, aponta um elevado consumo de carnes, com média per capita de carne bovina de $73,5 \mathrm{~g} /$ dia para os homens e 53,6g/dia para as mulheres. Sem contar, porém, o consumo de outros tipos de carne, como a suína e as processadas (hambúrguer, salsicha, dentre outras). Somando o consumo de todos os tipos de carnes, alcançou-se a ingestão média de 84,0g/dia para homens e mulheres (incluindo a carne bovina, suína, carnes salgadas, linguiça, salsicha, mortadela, presunto e outras carnes processadas) [23].

Para a produção de 1 quilograma de proteína animal é necessário em média $6 \mathrm{~kg}$ de proteína vegetal [24]. As necessidades de terras para a produção de proteína animal são, em média, 10 vezes maiores que para a produção de proteína vegetal. Aproximadamente $40 \%$ da colheita mundial de grãos são direcionadas à alimentação de animais, sendo 50\% desta quantia mais que suficientes para alimentar todas as pessoas em situação de IAN no mundo. A produção animal exige consideráveis recursos de energia e água e levam ao desflorestamento e uso intesivo de pastagens ${ }^{[4,25,26,27]}$. Além disso, no Brasil, a pecuária é considerada o segundo setor econômico a gerar maiores emissões de GEEs, principalmente devido à liberação de metano pela fermentação de ruminantes e manejo de dejetos [28]. O esterco, produzido em enormes proporções, possui altos níveis de nitratos potencialmente carcinogênicos e contaminam a água potável e os vegetais. Deste modo, a produção de carne torna-se responsável por desproporcional pressão ambiental, seja pela maior utilização de recursos, seja pela poluição [1]. Assim, ao buscar-se maneiras sustentáveis para a produção e consumo de alimentos, a cadeia de alimentos proteicos é um excelente ponto inicial ${ }^{[1,29]}$.

As emissões antropogênicas dos GEEs têm aumentado desde os tempos pré-industriais, com crescimento de $70 \%$ entre 1970 a 2004. No ano de 2004, o setor da agricultura, foi responsável, isoladamente, por cerca de $14 \%$ do total das emissões humanas, e tendem a aumentar juntamente com a taxa de consumo [30]. Entretanto, o conjunto destas emissões derivadas da agricultura depende das técnicas de produção, processos naturais em solos, e do metabolismo animal. Além disso, a agricultura mecanizada tem se responsabilizado por consideráveis emissões dos mesmos, como consequência da necessidade de combustíveis fósseis para a aplicação de insumos químicos e requerimentos de energia durante a irrigação e outras práticas agrícolas [24].

Dentre os principais GEEs associados ao sistema alimentar, o dióxido de carbono $\left(\mathrm{CO}_{2}\right)$ originase especialmente de fertilizantes, conversão de terra para colheita, combustão de maquinário e criação de animais; o óxido nítrico $\left(\mathrm{N}_{2} \mathrm{O}\right)$, deriva-se principalmente de fertilizantes químicos quem contém nitrogênio, esterco, fixadores de nitrogênio e conversão microbial em solos, e o metano $\left(\mathrm{CH}_{4}\right)$ origina-se especialmente da decomposição de matéria orgânica em condições privadas de oxigênio, da fermentação entérica de ruminantes, de esterco guardado e do crescimento de arroz sob condições de inundação $[9,31,32]$.

A principal fonte de emissões induzidas por humanos, geralmente, provém do uso de combustiveis fósseis na manutenção de colheitas, aplicação de pesticidas e fertilizantes, tratores e outros mecanismos de apoio à produção e transporte dos produtos [10,12,24]. No caso do Brasil, apesar de ser considerado um dos maiores emissores de GEEs contribuintes ao aquecimento global, a maior parte provém de queimadas ligadas ao desflorestamento do bioma Amazônico e não ao uso de combustíveis fósseis [18].

\section{USO DE ENERGIA, AGROTÓXICOS E FERTILIZANTES}

A prática agrícola intensiva é vista como insustentável, principalmente pelo uso de recursos não renováveis como combustíveis fósseis e a velocidade acelerada do uso dos recursos renováveis, ultrapassando sua taxa de reposição natural [33]. O consumo global de energia tende a aumentar de 2 a 3\% anualmente, de 1999 até 2020, principalmente em países em desenvolvimento [34]. Junto ao prospecto observado, crescem as preocupações referentes ao aumento da poluição e seus impactos na saúde humana e ambiental [9]. Entretanto, a agricultura tornou-se cada vez mais dependente de energia não renovável. Em alguns países, o total de energia usado na produção excede a energia produzida e acumulada nas próprias plantações. Assim, sem novas opções 
compatíveis ao ambiente, esta prática não se mostra sustentável [35].

Outra questão é a disponibilidade de alimentos fora de sua sazonalidade pelo mercado globalizado que faz com que ocorra aumento da necessidade de energia, especialmente para o transporte dos alimentos [5]. Desta forma, os combustíveis fósseis se tornam uma das principais fontes de energia da agropecuária industrial, sendo que a produção de carne é o setor que mais demanda energia [33], cerca de 2,5 a 5,0 vezes mais que as plantações [36].

Como apontaram Baroni et. al. [10], todo o processo de produção de carne envolve um elevado consumo de energia e grande geração de poluição ambiental, tornando o processo bastante ineficiente. Ao transformar vegetais em proteínas animais, a energia contida nos vegetais é desperdiçada ${ }^{[1,10]}$. Posteriormente à produção, toda a cadeia requer fornecimento de energia, obtido pela queima de combustíveis fósseis para transporte, processamento, embalagem, resfriamento, distribuição, dentre outros [33].

Se for considerado somente o consumo de combustíveis fósseis, a produção de uma caloria de carne necessita 40 calorias de combustível; uma caloria do leite precisa de 14 calorias de combustível, enquanto uma caloria de grãos pode ser obtida de 2,2 calorias de combustíveis fósseis [24,36]. Dentre as novas tecnologias em substituição aos combustíveis fósseis, encontram-se os biocombustíveis, produzidos a partir de fontes biológicas, como plantações agrícolas de milho, cana, trigo, sorgo, oleaginosas, além de outros, já em utilização em alguns países, incluindo o Brasil [18,37]. Esta nova tecnologia em ascensão provê benefícios tais como menor custo, potenciais benefícios a moradores e agricultores de áreas rurais e a possibilidade de diminuição nas emissões de GEEs. Entretanto, há controvérsias em relação a estes benefícios e sua produção também necessita áreas de cultivo, assim como o uso de água para a irrigação, gerando, assim, maior competição por terras agriculturáveis e água para a produção de biocombustíveis e de alimentos [38,16]. Colheitas de cana, por exemplo, são na sua maioria produzidas em monocultura com intensiva irrigação, gerando comprometimento da qualidade e fertilidade do solo, maior escassez e poluição de água. Além destes fatores, há a questão econômica, pois o preço dos alimentos pode aumentar pela utilização da terra para produção de biocombustível [37,38]. Sendo assim, ainda existem questões a serem debatidas sobre a viabilidade em longo prazo da adoção destas novas tecnologias.

A produção de fertilizantes sintéticos e minerais, especialmente à base de nitrogênio, consome grandes quantidades de combustíveis fósseis, principalmente gás natural, com liberação de quantidades significativas de $\mathrm{CO}_{2}{ }^{[39]}$. Há também o dispêndio de energia com o uso de máquinas que utilizam combustíveis fósseis [5]. Segundo a International Fertilizer Industry Association [31] do total mundial em emissão de GEEs, 2 a 3\% estão diretamente relacionado à produção, distribuição e uso de fertilizantes.

Deve se destacar também que a eficiência do uso de nitrogênio como fertilizante é baixa, e há, portanto, grande dispersão de amônia, nitratos e oxido nítrico no ambiente [16]. Do volume aplicado às plantações, estima-se que somente um terço ou metade seja absorvido [14]. Uma vez liberado, o nitrogênio vai para a atmosfera e ecossistemas aquáticos e terrestres, causando uma série de impactos negativos no ambiente e na população como a ocorrência de chuva ácida, desaparecimento de florestas, poluição de áreas costeiras, perda de biodiversidade, redução do ozônio atmosférico e o aumento dos efeitos dos GEEs [16,31,33].

Além dos fertilizantes, devido à necessidade de velocidade na produção para o abastecimento do mercado, produtores acabam optando pela monocultura [5,33]. Esta contribui para a o aumento da vulnerabilidade das plantações, necessitando de quantidades maiores de pesticidas que causam a contaminação da água, do solo [10], danos a espécies benéficas de insetos e resistência química pelas pestes [33].

O lixo orgânico gerado pela produção animal intensificada pode melhorar a qualidade e fertilidade, contribuindo para um solo biologicamente mais ativo, podendo substituir a utilização de fertilizantes [32]. Entretanto, seu uso resulta em poluição da água, do solo e do ar [29]. Estes dejetos, em sua maioria, não sofrem tratamento, contendo grandes concentrações de nitrogênio, fósforo e compostos de potássio e traços de metais e antibióticos, representando um sério problema de Saúde Coletiva [5,29]. 


\section{BIODIVERSIDADE E RECURSOS NATURAIS}

A biodiversidade vem enfrentando uma crise, com ameaça a inúmeras comunidades biológicas, principalmente pela influência de diversas atividades humanas [40]. Tal situação é comumente causada pela combinação de vários processos de degradação ambiental. A produção de alimentos, em especial a de animais, responsabiliza-se por parte desta situação por contemplar a mudança nos babitats e nos ecossistemas pelo uso, modificação e poluição de terras, leitos e superfícies de água, além do uso de nitrogênio presente nos fertilizantes, queima de combustíveis fósseis e a super exploração de pastos e espécies aquáticas $[8,9,34]$.

Para muitas espécies, assim como os peixes, os níveis de produção são limitados pela natureza ${ }^{[41,12]}$. Em revisão realizada por Oliveira, Luzia e Rondó [42], dados sobre produção e consumo de peixes foram contemplados. Além do declínio acelerado nas reservas de peixes nos últimos 50 anos, houve aumento nas recomendações de ingestão de peixe e de seu óleo, o que vem intensificando a pressão sobre as reservas naturais e contribuindo para a extinção de espécies [43]. A exploração das reservas de peixes ainda tem implicação na SAN de moradores de regiões costeiras de países menos desenvolvidos [44].

Além da pesca exploratória, a prática da aquicultura tem grande importância no fornecimento de peixe para consumo humano e vem se desenvolvendo mais rapidamente que a produção de outras carnes. Entretanto, ela envolve a utilização de pequenos peixes selvagens, como a anchoveta, capturados das reservas naturais, para a produção de ração [43]. Desta forma, é possível que essa alternativa não seja suficiente para manter $\mathrm{o}$ fornecimento sustentável para consumo humano. A substituição da composição da ração à base do óleo de pequenos peixes pelo de microalgas marinhas, fonte primária de ácidos graxos poli-insaturados ômega-3, seria uma opção que contribuiria para a conservação da biodiversidade e preservação de reservas de peixes selvagens, devendo ser aliada ao uso responsável para se evitar desequilibrio ambiental [42].

A agricultura é o setor de maior gasto de água doce, consumindo $70 \%$ do total, enquanto os setores industrial e doméstico consomem $20 \%$ e $10 \%$, respectivamente. Somente o setor de criação de animais conta com 8\% do uso antropogênico de água, sendo a maioria para a irrigação de plantações de ração, devendo ser a maior fonte de poluição da mesma. Ademais, as fontes de água doce estão escassas e geralmente de difícil acesso. Ainda, a retirada excessiva e seu mau gerenciamento resultam em menores níveis de água subterrânea e redução do contingente mundial [?].

A relação entre questões da escassez de água tem forte relação com o padrão atual de dieta, que se baseia em alimentos de origem animal. A maior parte da água da agricultura vai para a irrigação de cereais e sementes oleaginosas que são utilizadas na produção de ração, para hidratação das criações, para limpeza de estábulos e produções leiteiras, matadouros e assim por diante $[9,10]$.

Segundo dados apresentados na publicação da Barilla Center for Food and Nutrition [16], uma dieta à base de produtos de origem animal consome de 4000 a 5000 litros de água diários, enquanto uma alimentação sustentável gasta de 1500 a 2600 litros por dia, ou seja, cerca de 2500 litros que poderiam ser economizados pela escolha alimentar. Resultados concordantes foram anteriormente discutidos por Marlow et. al. [5], que destacaram que a dieta vegetariana ou vegana contribui com significativa redução no uso de água.

\section{CONSIDERAÇÕES FINAIS}

De acordo com a discussão, observa-se que os impactos gerados são muitas vezes fruto das condições de produção dos alimentos, sendo estas impulsionadas pelos padrões de consumo. Visando tornar o sistema alimentar mais sustentável, é preciso uma transição gradual. Entretanto, para que tal transição venha à tona, são necessárias proposições de mudanças rumo a padrões dietéticos mais adequados ao ambiente, como, por exemplo, a diminuição do consumo de produtos de origem animal, especialmente da carne bovina. Além disso, é imprescindível o apoio à pesquisa para que métodos sustentáveis de produção de alimentos sejam desenvolvidos, resgatados e valorizados, em especial as experiências agroecológicas e práticas de agricultura urbana e periurbana.

A mudança nos hábitos alimentares direcionada a uma dieta com maior participação de alimentos de origem vegetal parece ser indiscutível, entretanto as carnes, especialmente a bovina, são alimentos muito valorizados pela nossa sociedade. 
Desta forma, conhecer com profundidade os aspectos simbólicos relacionados a estes alimentos torna-se pertinente para qualquer intervenção educativa de cunho alimentar, nutricional e ambiental. $\mathrm{O}$ ato de comer é permeado por cultura, nele há uma trama complexa não composta apenas por fatores nutricionais, mas também por aspectos sociais, históricos, econômicos, políticos, geográficos, psicológicos; desvinculá-los reduz a profundidade do debate da questão alimentar atual e limita qualquer tentativa de pensar políticas públicas que tenham como objetivo a promoção da SAN, da Saúde Coletiva e Ambiental.

Há ainda muitas barreiras para que a discussão dos impactos ambientais da produção ao consumo de alimentos sejam considerados nas agendas das associações e instituições da área de Nutrição, Saúde Coletiva e Ambiente no Brasil. Portanto, outros estudos e esforços devem ser realizados com intuito de evidenciar esta inter-relação, tornando seu entendimento mais palpável e promotor de uma movimentação na sociedade civil, na academia e no Estado, rumo a outros sistemas de produção de alimentos e outros padrões dietéticos.

\section{REFERÊNCIAS}

[1] Aiking H, De Boer J. Backgrounds, Aims and Scope. In: Aiking H, De Boer J, Vereijken J. Sustainable Protein Production and Consumption: Pigs or Peas? Environment \& Policy. $1^{\mathrm{a}}$ ed. Holanda: Ed. Springer; 2006. v. 45.

[2] Pimentel D, Pimentel M. To improve nutrition for the world's population. Science. 2000;288:1966-1967.

[3] Rojstaczer S, Sterling SM, Moore NJ. Human appropriation of photosynthesis products. Science. 2001;294:2549-2552.

[4] Pinstrup-Andersen P, Pandya-Lorch R. Food security and sustainable use of natural resources: a 2020 vision. Ecol Econ. 1998;26:1-10.

[5] Marlow HJ, Hayes WK, Soret S, Carter RL, Schwab ER, Sabaté J. Diet and the environment: does what you eat matter?. Am J Clin Nutr. 2009;89:1699S-1703S.

[6] Leitzmann C. Nutrition Ecology: the contribution of vegetarian diets. Am J Clin Nutr. 2003;78:.657S-659S.

[7] Kac G, Proença RPC, Prado SD. A criação da área “nutrição" na Capes. Rev Nutr. 2011;24:905-916.
[8] Vitousek PM, Mooney HA; Lubchenco J, Melillo JM. Human Domination of Earth's Ecosystems. Science. 1997;277:494-499.

[9] Steinfeld H, Gerber P, Wassenaar T, Castel V, Rosales M, Haan C. Livestock's long shadow: environmental issues and options[internet]. Roma: FAO; 2006 [acesso em 26 set 2012]. Disponível em: http://www.globalwarminghype.com/livestocks_long_shad ow.pdf

[10] Baroni L, Cenci L, Tettamanti M, Berati M. Evaluating the environmental impact of various dietary patterns combined with different food production systems. Eur J Clin Nutr. 2007;61:279-286.

[11] Reganold JP, Glover JD, Andrews PK, Hinman HR. Sustainability of three apple production systems. Nature. 2001;410:926-930.

[12] Carlsson-Kanyama A, González AD. Potential contributions of food consumption patterns to climate Change. Am J Clin Nutr. 2009;89:1704S-1709S.

[13] Hoffman RC. Frontier Foods for Late Medieval Consumers: Culture Economy, Ecology. Environ His. 2001;7:131-167.

[14] Tilman D, Cassman KG, Matson PA, Naylor R, Polasky S. Agricultural sustainability and intensive production practices. Nature. 2002;418:671-677.

[15] Barilla Center for Food and Nutrition. Double Pyramid: healthy diet for all and sustainable for the environment [internet]; 2011 [acesso em 5 nov 2012]. Disponível em: http://www.barillacfn.com/wp/content/uploads/2012/07 /BCFN_DP2011_TECH_DOCUMENT.zip>

[16] Barilla Center for Food and Nutrition. Double Pyramid 2012: enabling sustainable food choices [internet]; 2012 [acesso em 5 nov 2012]. Disponível em: http://www.barillacfn.com/wp/content/uploads/2012/10 /pp_dp2012_eng.pdf.

[17] Food and Agriculture Organization. Sustainable Diets and Biodiversity [internet]. Roma; 2010 [acesso em 28 out 2012]. Disponível em: http://www.fao.org/docrep/016/i3004e/i3004e.pdf.

[18] Cerri CC, Maia SMF, Galdos MV, Cerri CEP, Feigl BJ, Bernoux M. Brazilian greenhouse gas emissions: the importance of agriculture and livestock. Sci. Agric. (Piracicaba, Braz.). 2009;66:831-843. 
[19] World Wildlife Fund. The year the world caught fire report [internet]; 1997 [acesso em 13 set 2012]. Disponível em:

http://www.equilibriumconsultants.com/upload/document /theyeartheworldcaughtfire.pdf.

[20] World Cancer Research Fund \& American Institute for Cancer Research. Food, Nutrition, Physical Activity, and the Prevention of Cancer: A Global Perspective [internet]. Washington, DC: AICR; 2007 [acesso em 19 out 2012]. Disponível em: http://eprints.ucl.ac.uk/4841/1/4841.pdf.

[21] Carvalho AM, César CLG, Fisberg RM, Marchioni DML. Excessive meat consumption in Brazil: diet quality and environmental impacts. Public Health Nutri. 2012;1-7.

[22] Brasil. Ministério da Saúde. Secretaria de Atenção à Saúde, Coordenação Geral da Política de Alimentação e Nutrição. Guia Alimentar para a População Brasileira: Promovendo a Alimentação Saudável. Brasilia: MS, 2006.

[23] Instituto Brasileiro de Geografia e Estatística. Pesquisa de Orçamentos Familiares 2008-2009: análise do consumo alimentar pessoal no Brasil. Rio de Janeiro: IBGE, 2011.

[24] Pimentel D, Pimentel M. Sustainability of meat-based and plant-based diets and the environment. Am J Clin Nutr. 2003;78:660S-663S.

[25] Pimentel D, Pimentel M. World population, food, natural resources and survival. World Futures: The Journal of Global Education. 1993;59:145-167.

[26] Pimentel D, Bailey O, Kim P, Mullaney E, Calabrese J, Walman L, Nelson F, Yao X. Will limits of the earth's resources control human numbers?. Environ Dev Sustain. 1999;1:19-39.

[27] Pimentel D, Pimentel M. Population growth, environmental resources and global food. J Sustainable For. 1999;9:35-44.

[28] Brasil. Ministério da Ciência e Tecnologia. Inventário Brasileiro das Emissões e Remoções Antrópicas de Gases de Efeito Estufa. Informações Gerais e Valores Preliminares [internet]; 2009 [acesso em 19 out 2012]. Disponível em: http://www.mct.gov.br/upd_blob/0207/207624.pdf.

[29] Delgado CL, Rosengrant MW, Steinfeld H, Ehui SK, Courbois C. Livestock to 2020: the next food revolution. Outlook Agric. 2001;30:27-29.

[30] Intergovernmental Panel on Climate Change. United Nations Environment Programme. Assessment Report 4: Contribution of Working Groups I, II and III to the Fourth
Assessment Report of the Intergovernmental Panel on Climate Change. Geneva: UN, 2007.

[31] International Fertilizer Association. Fertilizers and Climate Change: Enhancing Agricultural Productivity and Reducing Emissions. Feeding the Earth, 2009.

[32] Gartnett T. Livestock-related greenhouse gas emissions: impacts and options for policy makers. Environ Sci and Policy. 2009;12:491-503.

[33] Horrigan L, Lawrence RS, Walker P. How sustainable agriculture can address the environmental and human health harms of industrial agriculture. Environ Health Perspect. 2002;110:445-456.

[34] Cowling E, Galloway J, Furiness C, Erisman JW. Optimizing nitrogen management in food and energy production and environmental protection. In: Summary statement from the Second International Nitrogen Conference. Bolger Conference Center Potomac Maryland, USA [internet]; 2001 [acesso em 23 out 2012]. Disponível em: $\quad$ http://www.initrogen.net/fileadmin/userupload/Second-N-Conf_Report.pdf.

[35] Mcmichael AJ, Powles JW, Butler CD, Uauy R. Food, livestock production, energy, climate change, and health. Lancet. 2007;370:1253-1263.

[36] Reijinders L, Soret S. Quantification of the environmental impact of different dietary protein choices. Am J Clin Nutr. 2003;78:664S-668S.

[37] Dufey A. Biofuels Production, Trade and Sustainable Development: Emerging Issues. Sustainable Markets Discussion Paper Number 2. International Institute for Environment and Development, London, 2006.

[38] Fraiture C, Giordano M, Liao Y. Biofuels and implications for agricultural water use: blue impacts of green energy. Water Policy. 2008;10:67-81.

[39] Woods J, Williams A, Hughes JK, Black M, Murphy R. Energy and the food system. Philos Trans R Soc B. 2010;365:2991-3006.

[40] Primack RB, Rodrigues E. Ameaças à Diversidade Biológica. In: Primack RB, Rodrigues E. Biologia da Conservação. $1^{\mathrm{a}}$ ed, Londrina: Editora Planta; 2001.

[41] Alexandratos N. World agriculture towards 2010, an FAO Study [internet]. Chichester, UK: John Wiley and Sons, and Rome: FAO; 1995 [acesso em 20 nov 2012]. Disponível em: http://www.mpl.ird.fr/crea/tallercolombia/FAO/AGLL/pdfdocs/wat2010.pdf. 
[42] Oliveira JM, Luzia LA, Rondó PHC. Ácidos Graxos Poli-insaturados Ômega-3: saúde cardiovascular e sustentabilidade ambiental. Segurança Alimentar e Nutricional. 2012;19:89-96.

[43] Lee JH, Okeefe JH, Lavie CJ, Harris WS. Omega-3 fatty acids: cardiovascular benefits, sources and sustainability. Nat Rev Cardiol. 2009;6:753-758.
[44] Brunner EJ, Jones PJ, Friel S, Bartley M. Fish, human health and marine ecosystem health: polices in collision. Int J Epidemiol. 2009;38:93-100. 